\title{
COLOUR POLYMORPHISM, SELECTION AND THE SEX RATIO IN THE ISOPOD SPHAEROMA RUGICAUDA (LEACH)
}

\author{
A. A. KHAZAELI and D. J. HEATH \\ Department of Biology, University of Essex, Colchester CO4 $35 \mathrm{Q}$, \\ England
}

Received 2.x.78

\begin{abstract}
SUMMARY
A 3-year-study of a population of this estuarine isopod revealed seasonal changes in the frequency of the "pattern " colour morph. The changes were similar in all 3 years except for the summer period in 1976 which was characterised by abnormal climatic conditions. Changes in morph frequency coincided with changes in the sex ratio. Experiments in the laboratory and with animals in cages on the saltmarsh showed that frequency and sex ratio changes were due to selective mortality under conditions of low salinity and low temperature.
\end{abstract}

\section{IntRoduction}

THE study of temporal variation of morph frequencies in natural populations has produced a great deal of information on the strength of natural selection and the agencies through which it operates (Dobzhansky, 1947; Glarke and Murray, 1962; Strickberger and Wills, 1966; Bishop, 1969). Typically these studies have demonstrated that selection is acting at one stage of the life cycle, but they have not shown that the special types of selection necessary to maintain variation are operating. Despite a large amount of work on different species it is still true that "To the present moment no one has succeeded in measuring with any accuracy the net fitnesses of genotypes for any locus in any species in any environment in nature" (Lewontin, 1974). The reasons for this reside, to some extent, with the organisms which have been studied which usually fail to meet one or more of the criteria laid down by Lewontin (1974).

The isopod Sphaeroma rugicauda (Leach) is an animal which meets Lewontin's criteria in that it is annual, viviparous and forms semi-permanent pairs in the breeding season, and several workers have described temporal variations in morph frequency in this species. West (1964) described homogeneous changes in the frequencies of three morphs in a number of populations in Pembrokeshire over a 2-year period. Bishop (1969) showed that the frequency of the yellow morph doubled over the winter period in a population in the Dee estuary, the trend being reversed in the summer. He identified the winter selective agent as low temperature and low salinity which caused increased mortality amongst non-yellow animals. Heath (I974) showed consistent seasonal frequency changes of the yellow morph over 3 years in a Scottish population and was again able to confirm that selective mortality was one causative factor. None of these studies concerned themselves with the problem of the maintenance of the polymorphism, although all the evidence suggests that it is a stable condition, since in the long term morph frequencies do not change appreciably. The work 
presented in this paper forms part of a more detailed study into the factors affecting morph frequencies at all stages of the life cycle.

\section{Methods}

Samples of animals were taken from a saltmarsh at the head of Alresford creek, south-east of Colchester in Essex (Map Reference TM168 082194). The dominant vegetation at the site was Puccinellia martima and the marsh was flooded by tides above 5.6 metres in height (at Sheerness). The method of sampling was as described by Heath (1974). The pattern morph (described by West, 1964) was chosen for study because of its relatively high frequency $(0 \cdot 06-0 \cdot 20)$.

The sex ratio was estimated by sexing animals which were greater than $3.5 \mathrm{~mm}$ in length, in a subsample of the common grey morph. All pattern individuals above this length were sexed. Salinity and temperature of the tidal water at the surface of the marsh were recorded every 5 minutes as the tide rose, using a portable salinity/temperature meter.

Inspection of the environmental data and the frequency data suggested causal links between the two. In order to find out if there were any differences in the survival of the two morphs under physical conditions similar to those in the natural environment two experimental approaches were used. In the first, mortality of males and females of grey and pattern were compared in the laboratory. Twenty males and 20 females of the two morphs, matched for size were kept in $250 \mathrm{ml}$ of water at a salinity of 2 per cent, at two different temperatures, $0-3^{\circ} \mathrm{C}$ and $20^{\circ} \mathrm{C}$. Animals were fed on soaked rat food and leaves of Puccinellia. The number of animals still alive was recorded every 24 hours using criteria described by Jansen (1970) and Marsden (1973). Several replicates of each experiment were carried out.

The second experimental method was to expose animals to more natural conditions by placing them in cages on the saltmarsh. Twelve turves $(10 \times 20 \mathrm{~cm})$ were taken at random from the marsh and all the isopods were removed from them. Forty animals ( 10 males and 10 females of the pattern and the grey morph) were put on each turf which was then placed in a cage and returned to its original location on the saltmarsh. After a suitable period of time had elapsed the cages were returned to the laboratory and the surviving animals counted. This type of experiment was carried out using both animals matched for size and animals with size distributions reflecting those found in the natural population. In all cases experiments were set up using animals taken from the population before the population had been exposed to the environmental conditions which the experiment was designed to imitate, and before frequencies in the natural population had changed.

\section{Results}

\section{(i) Frequency data}

The changes in the frequency of the pattern morph for the 3 years November 1975-November 1976, 1976-1977 and November 1977-July 1978 are presented in fig. 1. The present paper will be concerned with the seasonal changes occurring from November-May. The June-September period embraces the breeding season when factors other than selective mortality may be operating. From November-May there is no recruitment to 


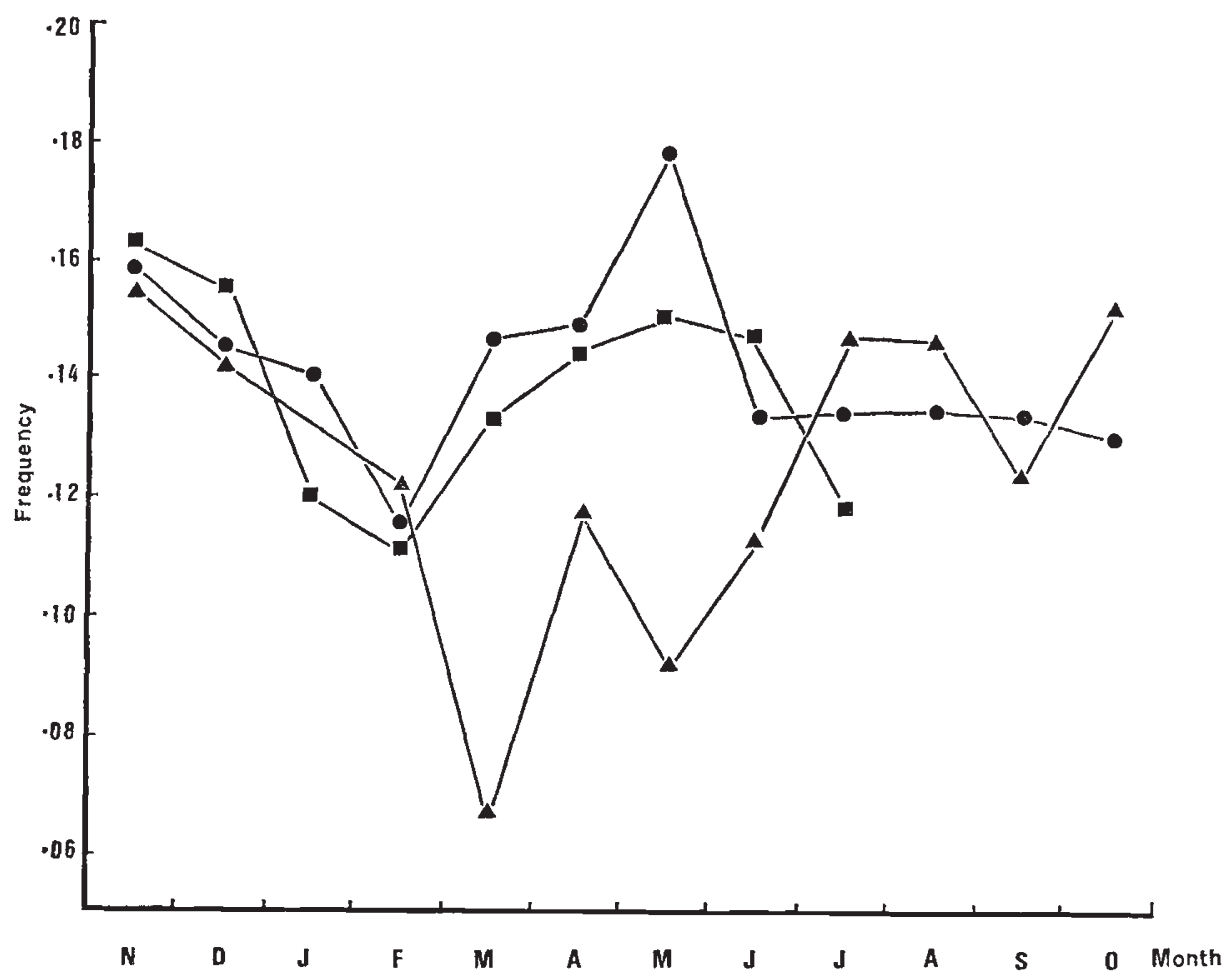

Fig. 1.-Mean monthly frequency of the pattern morph, November 1975-July 1978. $\Delta-\Delta, 1975-76 ;-0,1976-77: \square-\square, 1977-78$.

the population (apart from any migration) so that frequency changes are likely to be due to selective mortality (but see Discussion). Fig. 1 shows the mean monthly frequency of pattern for the 3 years, whilst table 1 gives the number of pattern and the sample size. Each monthly frequency represents the frequency calculated by pooling all samples collected within that month. Pooling the data in this way does not affect the shape of the curves significantly but makes them easier to follow. The relevant points to notice about these data are as follows. The frequency of pattern declines over the November-February period in all 3 years from around $0 \cdot 16$ to around $0 \cdot 12$. In 1976 the decline continued into March. After March in 1976 and after February in the other 2 years the frequency increased. Analysis by $\chi^{2}$ of differences between successive months in the same year (table 2) shows the statistical significance of these changes and overall changes are analysed by regression analysis in table 3 (a). Individual differences are not always significant but the similarity between the different years (apart from the period after February in 1976) suggests that real changes are occurring. Overall differences in frequency between November and February and February and May (except for 1976) are highly significant. Analysis of the differences between the same months in different years (table 2) shows that there are no differences between the 3 years over the November-February period. From February to May the frequencies in 1976 were consistently and significantly lower than in the corresponding months in the other 2 years. These low frequencies in the spring and early summer of 1976 were not 
TABLE 1

Sample size and total numbers of pattern, and numbers of male and female pattern

\begin{tabular}{|c|c|c|c|c|}
\hline Sampling date & Size sample & No. patt. & No. male & No. female \\
\hline $1: 11: 75$ & 781 & 121 & 24 & 27 \\
\hline $5: 12$ & 1205 & 173 & 29 & 47 \\
\hline $18: 2: 76$ & 514 & 63 & 17 & 39 \\
\hline $2: 3$ & 1700 & 114 & 26 & 64 \\
\hline $2: 4$ & 2333 & 277 & 59 & 133 \\
\hline $1: 5$ & 2419 & 216 & 47 & 130 \\
\hline $18: 5$ & 667 & 67 & 3 & 64 \\
\hline 1: 6 & 2079 & 234 & 35 & 86 \\
\hline $18: 6$ & 271 & 33 & 26 & 7 \\
\hline $1: 7$ & 264 & 39 & 10 & 28 \\
\hline $1: 8$ & 170 & 25 & 2 & 21 \\
\hline $1: 9$ & 2836 & 353 & 5 & 8 \\
\hline $8: 10$ & 841 & 118 & 41 & 61 \\
\hline $25: 10$ & 988 & 162 & 36 & 119 \\
\hline $7: 11$ & 1536 & 241 & 74 & 148 \\
\hline $23: 11$ & 140 & 27 & - & - \\
\hline $11: 12$ & 93 & 12 & - & - \\
\hline $21: 12$ & 856 & 126 & 27 & 84 \\
\hline $8: 1: 77$ & 39 & 7 & - & - \\
\hline $20: 1$ & 307 & 42 & 7 & 31 \\
\hline $7: 2$ & 629 & 67 & 11 & 51 \\
\hline 21: 2 & 473 & 61 & 9 & 43 \\
\hline $7: 3$ & 832 & 123 & 17 & 80 \\
\hline 18: 4 & 1276 & 191 & 44 & 105 \\
\hline $2: 5$ & 1554 & 203 & 94 & 87 \\
\hline $20: 5$ & 1026 & 215 & 63 & 100 \\
\hline $31: 5$ & 755 & 179 & 77 & 98 \\
\hline $17: 6$ & 1044 & 153 & 134 & 14 \\
\hline $30: 6$ & 349 & 33 & 30 & 3 \\
\hline 5: 7 & 643 & 82 & 42 & 7 \\
\hline 19: 7 & 311 & 46 & 31 & 15 \\
\hline $2: 8$ & 194 & 27 & l & 26 \\
\hline 18: 8 & 131 & 17 & 4 & 11 \\
\hline $1: 9$ & 594 & 99 & 一 & - \\
\hline 16: 9 & 853 & 96 & 2 & 5 \\
\hline $1: 10$ & 1098 & 137 & 11 & 29 \\
\hline $12: 10$ & 3808 & 502 & 68 & 192 \\
\hline $16: 11$ & 781 & 128 & 29 & 65 \\
\hline $9: 12$ & 1895 & 296 & 58 & 140 \\
\hline 13: $1: 78$ & 474 & 48 & 6 & 29 \\
\hline $24: 1$ & 1921 & 242 & 24 & 89 \\
\hline $22: 2$ & 637 & 72 & 13 & 57 \\
\hline $9: 3$ & 1246 & 149 & 14 & 91 \\
\hline $23: 3$ & 1674 & 222 & 57 & 125 \\
\hline $11: 4$ & 1445 & 211 & 58 & 149 \\
\hline $27: 4$ & 922 & 131 & 28 & 65 \\
\hline $8: 5$ & 1563 & 221 & 53 & 90 \\
\hline $28: 5$ & 1528 & 246 & 104 & 80 \\
\hline $7: 6$ & 1478 & 237 & 31 & 179 \\
\hline $26: 6$ & 633 & 75 & 59 & 11 \\
\hline 20: 7 & 530 & 63 & 25 & 28 \\
\hline
\end{tabular}

A dash (-) indicates that the pattern animals were not sexed usually because the number of mature animals was very small. 
Table 2

Mean monthly frequency of the pattern morph and $\chi^{2}$ value between consecutive months in the same year and between the same month in different years (in brackets). The final column represents the $\chi^{2}$ value between 1975-76 and 1977-78. (Significance levels, * $P<0.05 ; * * P<0.01 ; * * * P<0.001$ )

\begin{tabular}{|c|c|c|c|c|c|}
\hline \multirow[b]{2}{*}{1} & \multirow[b]{2}{*}{ Nov } & \multicolumn{2}{|c|}{$1975-76$} & \multicolumn{2}{|c|}{$1976-77$} \\
\hline & & $\begin{array}{c}0.1549 \\
(0.3991)\end{array}$ & $(0 \cdot 0651)$ & $\begin{array}{c}0 \cdot 1599 \\
(0 \cdot 8651)\end{array}$ & $(0.0366)$ \\
\hline 2 & Dec & $0 \cdot 1436$ & $(0 \cdot 0034)$ & $\begin{array}{c}0 \cdot 1454 \\
(0 \cdot 0068)\end{array}$ & $(0.4883)$ \\
\hline 3 & Jan & $\begin{array}{l}\text { No sample } \\
(1 \cdot 170)\end{array}$ & $(-)$ & $\begin{array}{c}0 \cdot 1416 \\
(1 \cdot 363)\end{array}$ & $(0.9942)$ \\
\hline 4 & $\mathrm{Feb}$ & $\begin{array}{c}0 \cdot 1226 \\
(15 \cdot 78) * * *\end{array}$ & $(0 \cdot 0837)$ & $\begin{array}{c}0.1162 \\
(3.938)\end{array}$ & $(0.0141)$ \\
\hline 5 & Mar & $\begin{array}{c}0.0671 \\
(12 \cdot 63) * * *\end{array}$ & $(42 \cdot 02) * * *$ & $\begin{array}{c}0.1478 \\
(0.0029)\end{array}$ & $(2 \cdot 267)$ \\
\hline 6 & Apr & $\begin{array}{c}0.1187 \\
(10 \cdot 18)^{* *}\end{array}$ & $(6 \cdot 731) * * *$ & $\begin{array}{c}0.1497 \\
(5 \cdot 395)^{*}\end{array}$ & $(0 \cdot 1402)$ \\
\hline 7 & May & $\begin{array}{c}0.0917 \\
(6 \cdot 805) * *\end{array}$ & $(102 \cdot 5) * * *$ & $\begin{array}{c}0 \cdot 1790 \\
(14 \cdot 38) * * *\end{array}$ & $(8 \cdot 854)^{* *}$ \\
\hline 8 & June & $\begin{array}{c}0 \cdot 1136 \\
(2 \cdot 352)\end{array}$ & $(3 \cdot 073)$ & $\begin{array}{c}0 \cdot 1335 \\
(0 \cdot 0002)\end{array}$ & $(1 \cdot 287)$ \\
\hline 9 & July & $\begin{array}{c}0.1477 \\
(0.0143)\end{array}$ & $(0 \cdot 2168)$ & $\begin{array}{c}0 \cdot 1342 \\
(0 \cdot 0020)\end{array}$ & $(0.5816)$ \\
\hline 10 & Aug & $\begin{array}{c}0.1471 \\
(0.5519)\end{array}$ & $(0.0481)$ & $\begin{array}{c}0.1354 \\
(0.0016)\end{array}$ & \\
\hline 11 & Sep & $\begin{array}{c}0 \cdot 1245 \\
(7 \cdot 522) * *\end{array}$ & $(0 \cdot 8194)$ & $\begin{array}{c}0 \cdot 1348 \\
(0 \cdot 0000)\end{array}$ & \\
\hline 12 & Oct & $\begin{array}{c}0 \cdot 1531 \\
(0.2585)\end{array}$ & $(0 \cdot 0000)$ & $\begin{array}{c}0 \cdot 1302 \\
(6 \cdot 251) * *\end{array}$ & \\
\hline 13 & Nov & 0.1599 & $(0 \cdot 0366)$ & 0.1639 & \\
\hline
\end{tabular}

\begin{tabular}{|c|c|}
\hline \multicolumn{2}{|c|}{$1977-78$} \\
\hline $\begin{array}{c}0.1639 \\
(0.9463)\end{array}$ & $(0 \cdot 1719)$ \\
\hline $0 \cdot 1562$ & $(0.8196)$ \\
\hline$(10.77)^{* *}$ & \\
\hline $0 \cdot 1210$ & $(-)$ \\
\hline$(0.2386)$ & \\
\hline 0.1130 & $(0 \cdot 1665)$ \\
\hline$(0 \cdot 8191)$ & \\
\hline 0.1271 & $(41 \cdot 16) * *$ \\
\hline$(3 \cdot 177)$ & \\
\hline $0 \cdot 1444$ & $(6.592) * *$ \\
\hline$(0.4113)$ & \\
\hline $0 \cdot 1511$ & $(50 \cdot 48)^{* * *}$ \\
\hline$(0.0822)$ & \\
\hline 0.1478 & $(11 \cdot 20)^{* * *}$ \\
\hline$(2 \cdot 677)$ & \\
\hline 0.1189 & $(1 \cdot 065)$ \\
\hline
\end{tabular}

(a) Frequency of pattern Period

November-March

November-February

November-February

March-April

February-April

February-April

(b) Frequency of male pattern

\section{TABLE 3}

Test for linear trend in proportions

\begin{tabular}{|c|c|c|c|c|}
\hline Period & Year & $b$ & $z$ & $\mathbf{P}$ \\
\hline $\begin{array}{l}\text { November-March } \\
\text { November-February } \\
\text { November-February }\end{array}$ & $\begin{array}{l}1975-76 \\
1976-77 \\
1977-78\end{array}$ & $\begin{array}{l}-0.0314 \\
-0.1667 \\
-0.0215\end{array}$ & $\begin{array}{r}7 \cdot 47 \\
10 \cdot 82 \\
3 \cdot 77\end{array}$ & $\begin{array}{l}<0.001 \\
<0.001 \\
<0.001\end{array}$ \\
\hline $\begin{array}{l}\text { March-April } \\
\text { February-April } \\
\text { February-April }\end{array}$ & $\begin{array}{l}1976 \\
1977 \\
1978\end{array}$ & $\begin{array}{l}0 \cdot 0512 \\
0 \cdot 0069 \\
0 \cdot 0163\end{array}$ & $\begin{array}{l}5 \cdot 22 \\
1 \cdot 06 \\
2 \cdot 39\end{array}$ & $\begin{array}{c}<0 \cdot 001 \\
0.289 \\
0 \cdot 0169\end{array}$ \\
\hline \multicolumn{5}{|c|}{ (b) Frequency of male pattern } \\
\hline $\begin{array}{l}\text { November-March } \\
\text { November-February } \\
\text { November-February }\end{array}$ & $\begin{array}{l}1975-76 \\
1976-77 \\
1977-78\end{array}$ & $\begin{array}{l}-0.0017 \\
-0.0084 \\
-0.0091\end{array}$ & $\begin{array}{l}0 \cdot 86 \\
3 \cdot 23 \\
3 \cdot 96\end{array}$ & $\begin{aligned} & 0.3898 \\
< & 0.001 \\
< & 0.001\end{aligned}$ \\
\hline $\begin{array}{l}\text { March-April } \\
\text { February-April } \\
\text { February-April }\end{array}$ & $\begin{array}{l}1976 \\
1977 \\
1978\end{array}$ & $\begin{array}{l}0.0099 \\
0.0083 \\
0.0093\end{array}$ & $\begin{array}{l}2 \cdot 20 \\
2 \cdot 59 \\
2 \cdot 82\end{array}$ & $\begin{array}{l}0.0278 \\
0 \cdot 0096 \\
0.005\end{array}$ \\
\hline
\end{tabular}

(c) Frequency of male pattern amongst non-juvenile pattern

$\begin{array}{lcrcc}\text { November-March } & 1975-76 & -0.0586 & 2.27 & 0.0232 \\ \text { November-February } & 1976-77 & -0.0567 & 3.50 & <0.001 \\ \text { November-February } & 1977-78 & -0.0501 & 2.44 & 0.0146 \\ \text { March-April } & 1976 & 0.0183 & 0.31 & 0.756 \\ \text { February-April } & 1977 & 0.0108 & 0.64 & 0.522 \\ \text { February-April } & 1978 & 0.0465 & 1.81 & 0.0588\end{array}$


carried through into the late summer, since by July there were no differences between the same months in different years.

\section{(ii) The sex ratio}

Fig. 2 shows the percentage of males amongst non-juvenile $(<3.5 \mathrm{~mm})$ pattern individuals (actual numbers can be found in table 1). The most striking features of this graph are the violent fluctuations in frequency of males from April onwards (these fluctuations being even more marked in the

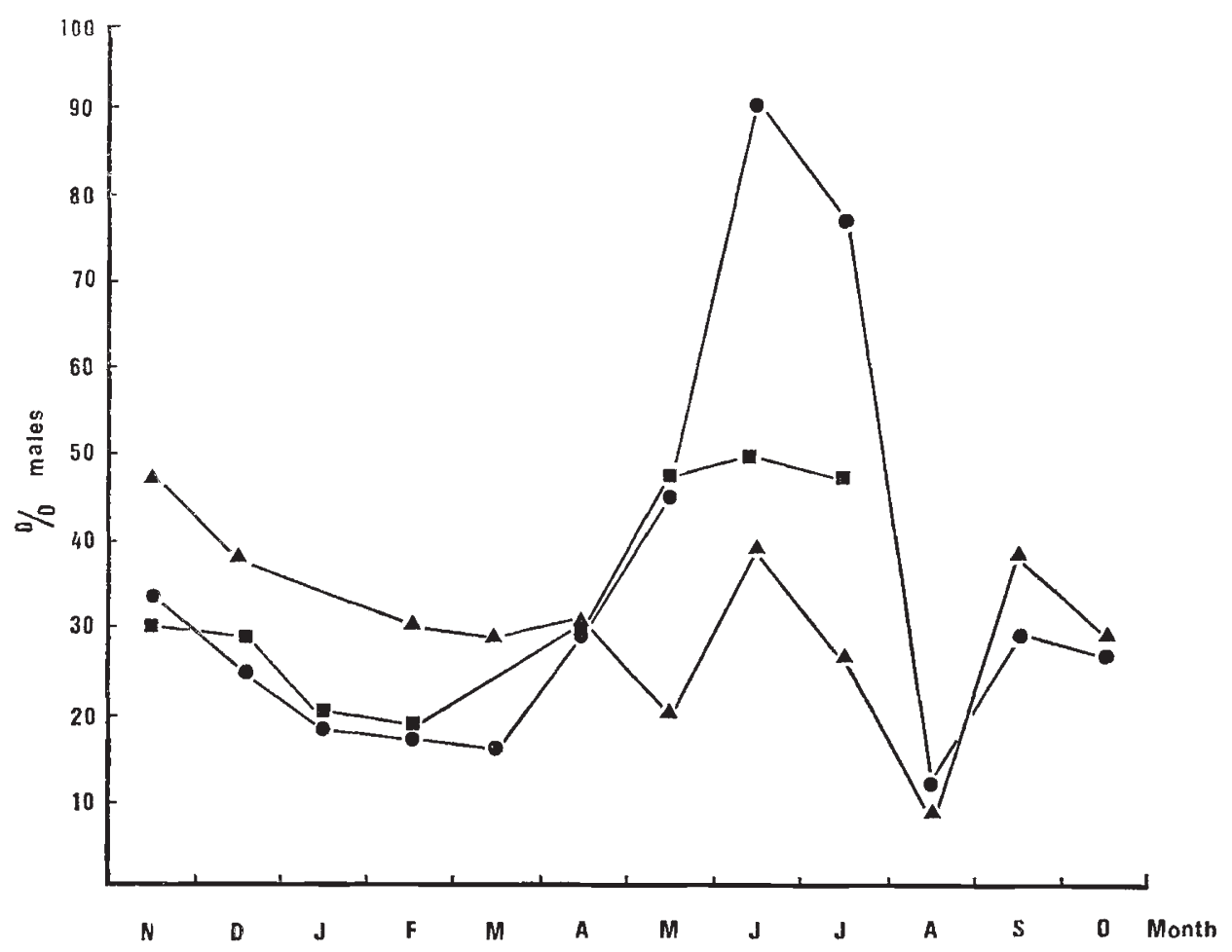

Fig. 2.-Percentage of male amongst matured individuals of the pattern morph, November 1975-July 1978.

$\Delta-\Delta, 1975-76$

1976-77;

1977-78.

original unpooled data). Most of these changes are not relevant to this paper since they occur outside the time period under consideration (NovemberMay). The first relevant point is that the period of time when pattern decreases in frequency (November-February/March) is characterised by a decline in the frequency of males amongst pattern animals. The results of linear regression analyses using the method for testing linear trends in proportions (Snedecor and Cochran, 1971) are given in table 3 (c). They show that in each year, over the period when pattern declined in frequency, there was a significant decrease in the proportion of male pattern. Thus, at the same time as pattern individuals became less frequent, so male pattern becomes less common relative to female pattern. This suggests that whatever the causative agent is, it has a greater effect on male pattern than on female pattern. 
There is little evidence that there is a subsequent increase in frequency of males amongst pattern (table 3(c)) although the frequency of pattern increases. Estimates of the sex ratio, derived from samples of swimming animals, are subject to serious biasses in the breeding season. Copulating animals in May and June are not sampled and this causes a decrease in the frequency of males amongst swimming animals because males are initially less common than females. Gravid females in June and July swim very little, raising the frequency of males which then falls as the females start to swim after releasing their young, and the males die.

Table 3 (b) however shows that male pattern do become more common relative to male grey over this period (February-April). Unless male pattern and male grey are behaving differently this suggests a real rise in the frequency of pattern males. These findings are consistent with the hypothesis that during this period the increase in the frequency of the pattern is due to equal increases in the frequency of male pattern and female pattern.

\section{(a) Salinity}

(iii) Environmental conditions

The data on seasonal variation in salinity are presented in fig. 3 . Salinities decrease over the autumn and winter periods and generally remain low $(<5 \%$ ) until the end of March. In 1975-1976 the

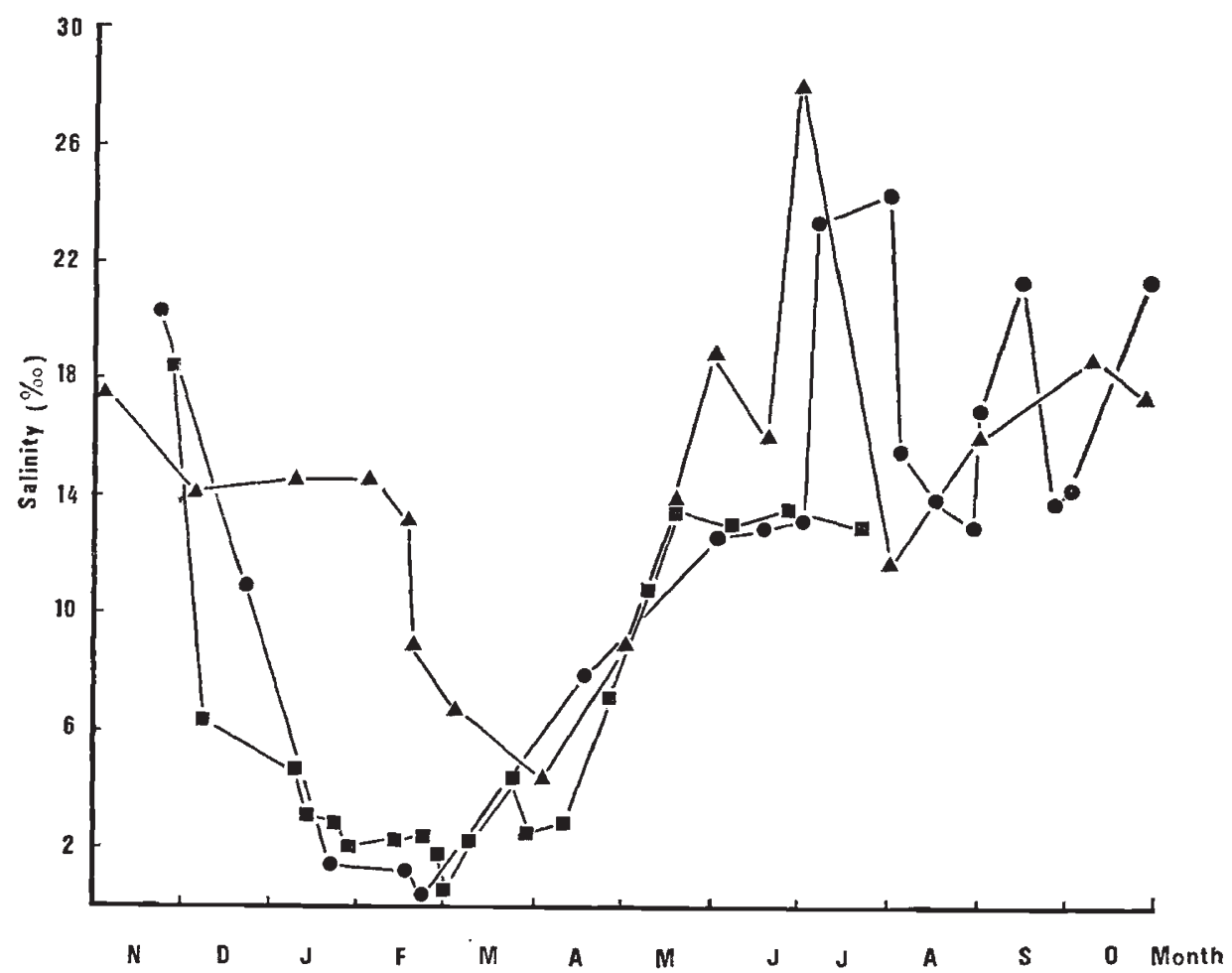

Fig. 3.-Recorded values of salinity at the surface of the salt-marsh, November 1975-July 1978. 
salinity remained high in the autumn and early winter and did not fall to typical winter levels until February/March. After April salinities rise to high values in the summer with maximum values of $24-28 \%$.

\section{(b) Temperatures}

In all 3 years water temperatures decline from $7-11^{\circ} \mathrm{C}$ in November to minimum values of $2-4^{\circ} \mathrm{C}$ in January and February (fig. 4). Thereafter they rise steadily to maximum values $\left(24-26^{\circ} \mathrm{C}\right.$ ) in June before declining over the late summer. The only major difference between years was in the summer of 1976. On this occasion temperatures rose sooner in the year

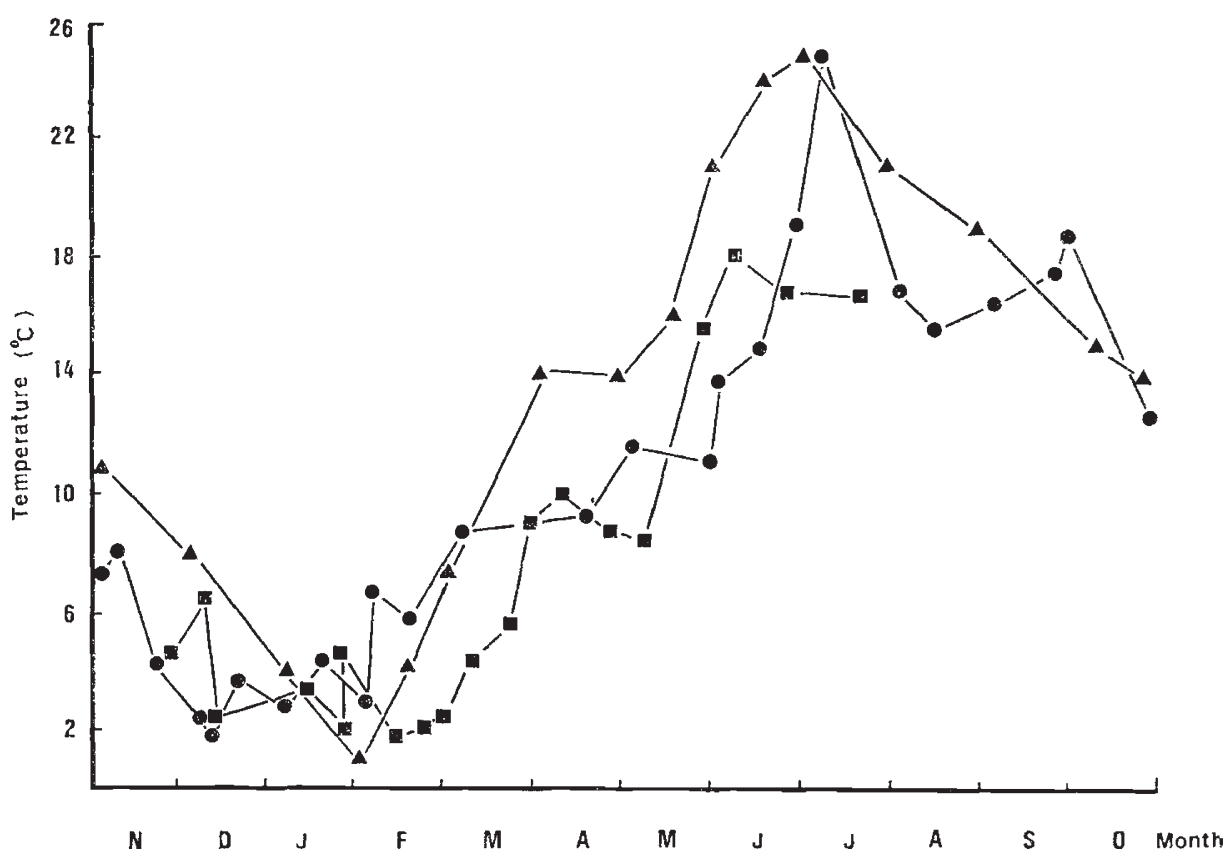

FIG. 4.-Recorded values of the water temperature at the surface of the salt-marsh, November 1975-July 1978.

$\Delta-\Delta, 1975-76$ , 1976-77; 1977-78.

such that for much of April, May and June temperatures were 2- $6^{\circ} \mathrm{C}$ hotter than in the corresponding period in the other 2 years.

These data on morph frequency, sex ratio and environmental parameters suggest that there is a decline in the frequency of pattern at a time of year when the salinity and temperature are low and that the decrease in frequency of pattern is most marked amongst males. The subsequent increase in the frequency of pattern coincides with higher temperatures and salinities.

\section{(iv) Experimental results}

(a) Laboratory experiments on the survival of male and female pattern and grey morphs at $0-3^{\circ} \mathrm{C}$ and a salinity of $2 \%$

The results of these experiments are detailed in table 4 (a) which gives the mean length of life (days) of the two sexes of the two morphs. Experi- 
TABLE 4

Survival of pattern and grey animals in the laboratory (animals matched for size)

(a) At $0-3^{\circ} \mathrm{C}$ and $2 \%$.

\begin{tabular}{|c|c|c|c|}
\hline \multicolumn{4}{|c|}{ Mean length of life (days) } \\
\hline \multicolumn{2}{|c|}{ Pattern } & \multicolumn{2}{|c|}{ Grey } \\
\hline $0^{\pi}$ & q & $\delta$ & 우 \\
\hline .40 & $20 \cdot 60$ & $22 \cdot 95$ & $22 \cdot 75$ \\
\hline 55 & $18 \cdot 20$ & 17.90 & $23 \cdot 65$ \\
\hline $5 \cdot 45$ & $21 \cdot 40$ & $22 \cdot 95$ & $24 \cdot 35$ \\
\hline $7 \cdot 90$ & $20 \cdot 70$ & $24 \cdot 00$ & $23 \cdot 50$ \\
\hline $9 \cdot 55$ & & 24.85 & \\
\hline $7 \cdot 90$ & & $21 \cdot 40$ & \\
\hline 8.25 & & $19 \cdot 50$ & \\
\hline 6.55 & & $21 \cdot 05$ & \\
\hline
\end{tabular}

\begin{tabular}{|c|c|c|c|c|c|}
\hline \multicolumn{6}{|c|}{ Mann-Whitney " $U$ " Test } \\
\hline \multicolumn{3}{|c|}{ Male pattern/female pattern } & \multicolumn{3}{|c|}{ Female pattern/female grey } \\
\hline $\mathrm{U}$ & $\mathbf{z}$ & $\mathbf{P}$ & $\mathrm{U}$ & $\mathbf{z}$ & $\mathbf{P}$ \\
\hline $136 \cdot 5$ & $3 \cdot 43$ & $<0.001$ & $174 \cdot 5$ & $2 \cdot 68$ & $<0.01$ \\
\hline 255 & $1 \cdot 12$ & n.s. & 94 & $4 \cdot 24$ & $<0.001$ \\
\hline $110 \cdot 5$ & 3.92 & $<0.001$ & $151 \cdot 5$ & $3 \cdot 12$ & $<0.01$ \\
\hline 214 & 1.91 & 0.056 & $177 \cdot 5$ & $2 \cdot 62$ & $<0.01$ \\
\hline
\end{tabular}

Wilcoxon signed rank test on male pattern compared to male grey, $T=0 . P<0.01$

(b) At $20^{\circ} \mathrm{C}$ and $2 \%$

$\begin{array}{lrrrr}\text { 1. } & 19 \cdot 35 & 19 \cdot 80 & 20 \cdot 85 & 18 \cdot 65 \\ \text { 3. } & 21 \cdot 40 & 15 \cdot 50 & 22 \cdot 00 & 12 \cdot 95 \\ \text { 4. } & 20 \cdot 15 & 19 \cdot 60 & 16 \cdot 60 & 11 \cdot 45 \\ \text { 5. } & 13 \cdot 35 & 14.25 & 20 \cdot 70 & 20 \cdot 65 \\ 6 . & 14 \cdot 00 & 13 \cdot 15 & 13 \cdot 55 & 13 \cdot 35 \\ \text { 7. } & 12 \cdot 70 & 12 \cdot 65 & 13 \cdot 80 & 11 \cdot 80 \\ 8 . & 14 \cdot 00 & 11 \cdot 45 & 13.55 & 12 \cdot 15 \\ \text { 8. } & & & & 10 \cdot 65\end{array}$

Wilcoxon signed rank test;

$\begin{array}{lcc} & T & P \\ \text { Male pattern/male grey } & 16.5 & \text { n.s. } \\ \text { Female pattern/female grey } & 13 & \text { n.s. } \\ \text { Male pattern/female pattern } & 2 & 0.02\end{array}$

ments 1-8 show that pattern males have significantly shorter mean lengths of life than grey males when analysed by the Wilcoxon signed rank test ( $T=0, n=8, p=0.01$ ) (Siegel, 1959). Female pattern also survive less well than female grey when mean lengths of life are compared using the Mann-Whitney test (Elliott, 1971). In all of the four comparisons between mean length of life of male pattern and female pattern, males had a shorter mean length of life, this difference was significant in two experiments, approached significance in a third experiment and was not significant in a fourth experiment.

Subject to the limitations of this experiment (i.e. the simplification of the environmental parameters compared to the natural environment and the use of matched size animals) it does confirm that pattern animals survive these conditions less well than grey. There is also good evidence that male pattern survive less well than female pattern. These results are confirmed by the more realistic cage experiments.

(b) Cage experiments on the survival of the two morphs in the field (animals matched for size)

The results of this experiment are given in table 5 (a). They show that pattern overall survives less well than grey and that male pattern survives 
less well in the cage than male grey and female pattern. The frequency of pattern within the cage declines because of this higher mortality of male pattern, and thus the change in frequency within the cage parallels that outside the cage. The only major drawback to this experiment lies in its use of individuals matched for size. The size distribution of different morphs are not the same in the wild (Khazaeli, unpublished) and mortality under

\section{TABLE 5}

Results of cage experiments in the field

(a) Survival of pattern and grey animals, matched for size

\begin{tabular}{|c|c|c|c|c|c|c|}
\hline \multirow[b]{2}{*}{ Date } & \multicolumn{2}{|c|}{ Pattern } & \multicolumn{2}{|c|}{ Grey } & \multirow{2}{*}{\multicolumn{2}{|c|}{$\begin{array}{l}\text { Frequency of } \\
\text { pattern }\end{array}$}} \\
\hline & o & 우 & $\sigma^{*}$ & 오 & & \\
\hline \multirow{3}{*}{$\begin{array}{r}7: 11: 77 \\
16: 1: 78\end{array}$} & 120 & 120 & 120 & 120 & & 0.500 \\
\hline & 60 & 102 & 92 & 110 & & $0 \cdot 445$ \\
\hline & & & & $\chi^{2}$ & d.f. & $\mathrm{P}$ \\
\hline \multicolumn{3}{|c|}{ Pattern/grey } & & 17.29 & 1 & $<0 \cdot 001$ \\
\hline \multicolumn{4}{|c|}{ Male pattern/male grey } & $17 \cdot 24$ & 1 & $<0.001$ \\
\hline \multicolumn{4}{|c|}{ Female pattern/female grey } & 1.98 & 1 & n.s. \\
\hline \multicolumn{4}{|c|}{ Male pattern/female pattern } & 31.93 & 1 & $<0.001$ \\
\hline
\end{tabular}

(b) Survival of pattern and grey animals, natural size distribution

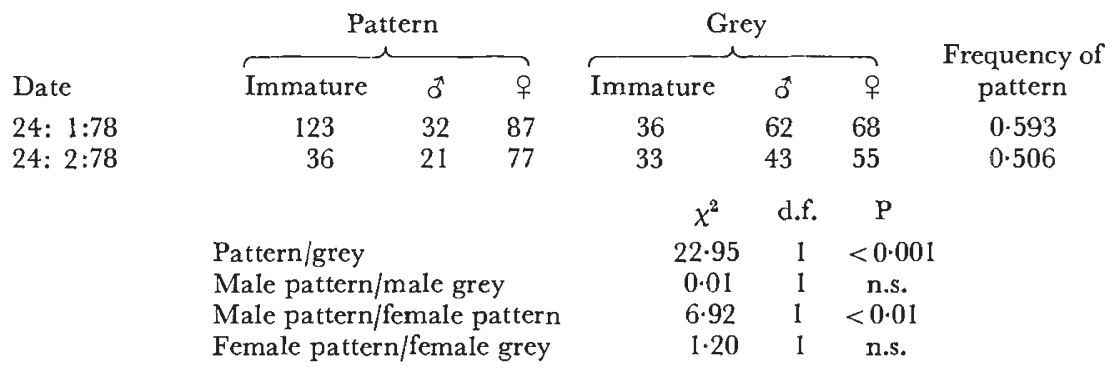

(c) Survival of pattern and grey animals, natural size distribution

\begin{tabular}{|c|c|c|c|c|c|c|c|}
\hline \multirow[b]{2}{*}{ Date } & \multicolumn{3}{|c|}{ Pattern } & \multicolumn{3}{|c|}{ Grey } & \multirow{2}{*}{$\begin{array}{l}\text { Frequency of } \\
\text { pattern }\end{array}$} \\
\hline & Immature & o & $q$ & Immature & $d$ & q & \\
\hline 28: $2: 78$ & 43 & 42 & 118 & 45 & 77 & 101 & 0.476 \\
\hline $7: 4: 78$ & 34 & 48 & 99 & 29 & 48 & 70 & 0.552 \\
\hline & attern/grey & & & $\begin{array}{r}\chi^{2} \\
31 \cdot 1\end{array}$ & $\begin{array}{c}\text { d. } f \\
1\end{array}$ & $\begin{array}{c}P \\
<0.001\end{array}$ & \\
\hline
\end{tabular}

salinity and temperature stress is known to be affected by size (Heath, 1973). The use of experimental animals with natural size distributions overcomes this problem.

(c) Survival of male and female of the two morphs in cages using natural size distributions

In this experiment a subsample of grey animals and all of a sample of pattern animals (as collected from the wild) were placed in the cages. The results of this experiment are given in table 5 (b). Once again the pro- 
portion of pattern animals surviving is lower than the proportion of grey. Male pattern also survive less well than female pattern. In this experiment most of the mortality seems to have occurred amongst the immature $(<3.5 \mathrm{~mm}$ in length) pattern, since a large fraction of these have disappeared. Their disappearance cannot be attributed to their recruitment into the mature section of the population since the number of mature animals does not increase. In fact growth rate over this period is generally low (Bishop, 1969).

(d) Survival of males and females of the two morphs in the laboratory at $20^{\circ} \mathrm{C}$ and $2 \%$ (animals matched for size)

This experiment, designed to investigate possible causal connections between the rise in the frequency of pattern in the early summer and the prevailing environmental conditions yielded the results given in table 4 (b). Inspection of this table shows no conspicuous, consistent differences between morphs or between sexes although the Wilcoxon signed rank test indicates a significantly longer mean length of life for male pattern when compared to female pattern. This would be consistent with an increase in the proportion of males amongst pattern in the wild.

\section{(e) Survival of pattern and grey in cages, using natural size distributions}

The results of this experiment, set up before pattern had increased in frequency in the population gave the results shown in table 5 (c). Pattern survived significantly better than grey overall. It is not meaningful to analyse the sex ratio changes in any detail since the animals are growing in size during this period and there will have been recruitment from the immature section of the population to the males and females. The figures for surviving males and females then represent the joint effects of survival and recruitment, but this does not apply to the morph frequencies, since both morphs are clearly distinguishable in the immature animals.

The experimental results can therefore be summarised as follows. Environmental conditions of salinity and temperature, which coincide with a decrease in the frequency of pattern and particularly male pattern, cause increased mortality of male and female pattern in relation to male and female grey in the laboratory. Exposure of animals matched for size and of animals with natural size distributions in cages in the field confirms that pattern decreases in frequency with a higher mortality of male pattern relative to female pattern. Cage experiments later in the year showed an enhanced survival of pattern compared to grey but the accompanying laboratory experiments were inconclusive.

\section{Discussion}

The results from the field data show that pattern decreases in frequency over the November-February period and at the same time male pattern becomes less common. The changes in frequency are too large and consistent to be due to random changes. The fact that the cage experiments showed lowered survival ability of pattern indicates that the frequency changes cannot be due to differential migration of morphs, selective predation by large predators (birds, crabs etc.) or to biassed sampling. The 
laboratory experiments suggest that the salinity and temperature conditions known to prevail in the natural situation at this time are the selective agents. Pattern is therefore at a selective disadvantage in the winter because of its higher mortality in low temperatures and low salinities, this effect being most marked in pattern males. It could be argued that the decline in the frequency of pattern males is an artefact, caused by behavioural differences between the two sexes. However, random samples taken in quadrats at low tide also show that male pattern becomes less common (Khazaeli, unpublished). Since the results of two different sampling methods agree the decline in male frequency is most unlikely to be an artefact. Alternatively the change in sex ratio could be due to unequal recruitment of the two sexes from the immature section of the population, which cannot be sexed. If females matured faster or if there were more immature females than males amongst these animals then their recruitment to the mature animals would depress the frequency of males. However, immature animals grown in the laboratory show no evidence of biassed sex ratios (Khazaeli, unpublished). Although no studies on maturation rates have been done, there is little growth over this period (Bishop, 1969). On the other hand, the experiments which show differential survival of the two sexes provide a direct explanation for the change in sex ratio.

Pattern subsequently rises in frequency, although there is little evidence that the sex ratio changes amongst pattern. Since this period runs into the breeding season, when males apparently become more common anyway, any increase in the frequency of male pattern amongst pattern individuals over this period may be an artefact. This is rendered less likely by the analysis in table 3 (b) which shows that the proportion of pattern males amongst non-pattern males increases over this period. This increase coincides with higher salinities and temperatures but the experimental evidence for a causative link is not good. Experimental animals in cages show an increase in pattern frequency but this does not identify the factor responsible, although it excludes certain possibilities such as large predators, migration etc. The laboratory experiment on survival under relevant temperature and salinity conditions was inconclusive.

The frequency data presented here strongly recall those of Bishop (1969) and Heath (1974). They demonstrated strong, seasonal selective mortality against the yellow morph of S. rugicauda. This caused a decrease in frequency followed by an increase. In parallel with the work by Heath (1974) which also showed that morph frequencies of yellow were stable from year to year, the frequency of pattern in Alresford Creek is similar in different years, despite the large fluctuations within years. This is not true for the period March-June 1976, when pattern frequencies were lower than in the other 2 years. Since the period was characterised by unusually high temperatures and low rainfall it is perhaps not surprising that the frequencies in this year were different from the other 2 years which were more typical and similar in their weather patterns. Quite why the long hot summer of 1976 should be associated with a low frequency of pattern is not clear. However, despite the lower frequencies in summer 1976, the frequency had reverted to average by late summer. The fact that decreases in frequency are followed by increases and that overall frequencies are more or less constant over short periods (3 years) and over longer periods (10 years) (Heath, 1974) suggests that the polymorphism is stable. Work on a related marine species $S$. 
serratum suggests a similar stability (Bocquet and Teissier, 1969; Hoestlandt and Trollé-Sciacchitano, 1978). It is, therefore, relevant to enquire what mechanisms might be involved in balancing the polymorphism.

Bishop (1969) and Heath (1974) both favoured an explanation based on two opposing selective forces, which alternately place one morph at an advantage and then at a disadvantage. The problem with this explanation is, that if the selective forces are components of the physico-chemical environment, then the situation is analogous to the maintenance of a stable population density by density independent factors. A true stable polymorphism can only be maintained under a set of restrictive conditions, although such fluctuating selective pressures may act to delay the loss of variation (Cook, 1971). Thus one could imagine a series of winters with abnormally low salinities and low temperatures which would progressively reduce the frequency of pattern, the opposing selective force being too small to correct this downward trend.

\section{REFERENCES}

BISHop, J. A. 1969. Changes in the genetic constitution of a population of Sphaeroma rugicauda (Crustacea : Isopoda). Evolution, 23, 589-601.

BocQUet, C., AND TEISSIER, G. 1960. Génétique des populations de Sphaeroma serratum (F.). 1. Stabilité du polychromatisme local. Cahiers Biol. Mar., 1, 103-111.

ClARKE, B., AND mURRAY, J. 1962. Changes of gene-frequency of Cepaea nemoralis (L). Heredity, 17(4), 445-465.

Cоoк, L. M. 1971. Coefficients of Natural Selection. Hutchinson \& Co., Ltd., London.

DOBZHANSKY, TH. 1947. Genetics of natural populations, XIV. Genetics, 35, 288-302.

ELLIOTT, J. M. 1971. Some methods for the statistical analysis of samples of benthic invertebrates. Freshwater Biological Association. Scientific publication No. 25.

HEATH, D. J. 1973. Ecological factors affecting gene frequency in a polymorphic isopod, Sphaeroma rugicauda (Leach). Ph.D. thesis, University of Edinburgh.

HEATH, D. J. 1974. Seasonal changes in frequency of the "Yellow" morph of the isopod Sphaeroma rugicauda. Heredity, 32, 299-307.

hoEsTLANDT, H., AND TROLLÉ-sciacChitano, F. 1978. Stabilité du polychromatisme de l'Isopode intertidal, Sphaeroma serratum, à la limite nord-est de son extension. Comptes Rendus Series D, 286. (14), 1117-1121.

JANSEN, K. P. 1970. Effect of temperature and salinity on survival and reproduction in Baltic populations of Sphaeroma hookeri Leach, 1814, and S. rugicauda Leach 1814, Isopod. Ophelia, 7, 177-185.

LEWONTIN, R. C. 1974. The Genetic Basis of Evolutionary Change. Columbia University Press. New York and London.

MARSDEN, I. D. 1973. The influence of salinity and temperature on the survival and behaviour of the isopod Sphaeroma rugicauda from a saltmarsh habitat. Marine Biology, 21, 75-85.

SIEgel, s. 1959. Non Parametric Statistics for the Behavioral Sciences. McGraw-Hill Book Company, Inc.

SNEDECOR, G. W., AND Cochran, w. G. 1971. Statistical Methods. The Iowa State University Press.

STRICKBERGER, M. W., AND WILLs, c. J. 1966. Monthly frequency changes of Drosophila pseudoobscura third chromosome gene arrangements in a California locality. Evolution, 20, 592-602.

WEST, D. A. 1964. Polymorphism in the isopod, Sphaeroma rugicauda. Evolution, 18, 671-684. 